\title{
A universidade do saber encontrado em bibliotecas: ontem, hoje e amanhã
}

Úrsula Blattmann

Graça Maria Fragoso

\section{Resumo}

Reflexão crítica sobre bibliotecas como templo dos saberes, suas facetas e mudanças. Debate sobre políticas de acesso de acervos públicos e privados. Importância de bibliotecas para atender o ser humano em suas dimensões sociais, educacionais, culturais, econômicas.

\section{Palavras-chave}

Biblioteca; Acervos - organização; Coleções - organização; Bibliotecário

\section{The universal knowledge to be found in libraries: yesterday, today and tomorrow}

\begin{abstract}
A critical reflection about libraries as knowledge temple, its facets and changes. Debates some political aspects of public and private access to libraries' collections. Importance of libraries to take care of the human being in its social, educational, cultural and economic dimensions.
\end{abstract}

\section{Keywords}

Library; Collection - organization; Librarian 


\section{CONTEXTO HISTÓRICO}

Para a concepção deste texto partiu-se do convite dos editores da Revista Digital Biblioteconomia e Ciência da Informação, a fim de traçar algumas reflexões referentes ao clássico de Umberto Eco, o livro O Nome da Rosa ou filme adaptado da respectiva obra. Uma nova leitura e uma série de análises sobre a biblioteca de ontem, hoje e amanhã.

A obra lançada há um quarto de século e o filme há duas décadas, continuam sendo um enredo pertinente, provocativo, atual e educativo. Remetem a uma biblioteca da abadia da Itália setentrional na época da Idade Média, resgatando o contexto descrito no manuscrito do monge germânico Adson de Melk, os aspectos do ambiente teológico, social, político, educacional de 1.314 a 1.327 . Percebem-se as motivações das pessoas em "os homens dessa terra corrompida estão sempre inclinados a favorecer os interesses seus, e são incapazes de olhar para o mundo inteiro como sua pátria espiritual” (ECO, p. 22-23).

As bibliotecas surgem de coleções literárias, contábeis, teológicas, filosóficas, científicas. Enfim, o saber registrado em seus diversos suportes, formatos e tipologia documental atendem os detentores de poder conforme inseridos no seu tempo e espaço. Espelham valores sociais e representam a cultura, a educação, a economia e o lazer da civilização em sua época e contexto.

A Idade Média contribui na evolução da sociedade por ter construído os alicerces das universidades para a formação do ser humano. Estas, oriundas de acervos teológicos, mantenedoras do poder no ocidente baseado no cristianismo, mostravam-se receptivas em acolher por meio de esforços a ampliação constante do acervo seja por permutas, doações e renovação, seja por cópias de obras, e ser o diferencial entre as demais. Para manter esse status quo, empreendia-se um ambiente projetado para a reprodução dos documentos da época, envolvendo no Scriptorium uma equipe de profissionais na reprodução, de copistas a miniaturistas (ilustradores), de tradutores aos escribas, de autores aos leitores. 
Enquanto no Edifício no qual a biblioteca estava localizada somente o abade, o bibliotecário e seu ajudante poderiam percorrê-la. O cargo de bibliotecário envolvia a representação de uma função política que passaria a ser o futuro abade. Mistérios na condução das direções de bibliotecas sempre existiram, por indicação, mérito, políticas ou politicagens. Estes ingredientes persistem e questionam quais serão as novas maneiras de administrar os ambientes de acesso e de uso da informação em seus modos e rituais.

O observar de atos, ações e atitudes do administrador de acervos revela o seu jugo e sua missão em dinamizar as facetas da biblioteca. Assim mencionava Ortega y Gasset : a biblioteca é um ser vivo.

Battles (2003, P. 16-17) resgata a magia envolvente desse ambiente fascinante e encantador "Reunidos aos milhões, empilhados, puídos, lidos e esquecidos, os livros de uma biblioteca vão ganhando uma vida própria, não exatamente como textos, mas como objetos físicos do mundo”.

Tipologias documentais surgem da evolução do conhecimento, dessa necessidade ímpar de organizar os saberes, de aproveitar recursos escassos, de ampliarem técnicas de produção e reprodução, em catalogar e classificar acervos (mesmo que poucos consigam decifrar, pois parecem mais enigmas que sistemas hierárquicos), dinamizar recursos materiais e humanos, desenvolver métodos (instrumentos e técnicas) e buscar novas tecnologias para promover a memória via escrita e leitura.

Nos últimos séculos a humanidade deu grandes saltos no uso e diversificação dos meios de comunicação, registrados ou transmitidos: das cartas aos incunábulos, do desenvolvimento da imprensa ao telégrafo, do telefone ao fax, do computador aos produtos convergentes das multimídias reunidas na tela do computador.

A preocupação consiste na preservação da memória, da cultura, dos saberes, seja para organizar, disseminar, acessar, recuperar ou para usar a informação registrada. 
A modernização da biblioteca poderá ser vista na profissionalização das atividades e competências, na otimização do tempo, dos recursos, em busca da eficiência, do controle do espaço e acesso no qual se objetiva deixar o acervo preparado para o uso.

\section{O AMBIENTE DA BIBLIOTECA}

Cada período da história tem proporcionado aspectos inovadores na biblioteca, ou seja, pode-se acompanhar a evolução do acervo, da administração, dos recursos, observando-se o contexto influenciado pelos detentores de poder(es).

Assim se deu a importância do clero no desenvolvimento das universidades medievais. O ensinar multifacetado contribuía para educar amplamente o ser humano na crença, na cultura e na ciência. No cenário da biblioteca na Idade Média, ao lado o Scriptorium, a biblioteca era considerada o labirinto do saber. A pessoa responsável pelo acesso à organização e ao atendimento estava pautada na censura, na autorização do acesso ou não às obras do acervo.

Requisitos essenciais no manejo consistiam em saber ler e escrever nos idiomas latim, grego e árabe, além de operacionalizar atividades de organização para efetuar o registro do acervo, sua localização e procedência.

No século 21, passados mais de meio milênio em relação à biblioteca descrita no romance de Eco, permeiam políticas de acesso à informação e respectivo uso conforme os interesses dos detentores do poder, agora multifacetados não apenas pelo clero, mas também pelas diferentes categorias de governos, das instituições militares, civis, econômicas e de ensino e pesquisa nos quais se situam as universidades.

Bibliotecas de famílias reais foram transformadas em Bibliotecas Nacionais como a da Holanda, a de Portugal, a do Brasil. Outras, oriundas do poder representativo de democracias se tornaram universais. Do poder público emergem bibliotecas públicas 
estaduais, municipais, comunitárias para atender o cidadão. Também bibliotecas especializadas por áreas do conhecimento (de direito, de medicina) ou para atender ambientes educacionais (escolares e universitárias). Alterações nas denominações representam o vínculo institucional ou a inserção de novas tecnologias da informação e comunicação, no qual bibliotecas estão disponíveis na rede de computadores e com acesso 24/7 (vinte e quatro horas abertas nos sete dias da semana, durante o ano todo).

Bibliotecas representam coleções que podem ser singulares, simples, única, complexas e plurais. A pergunta que surge: quais e como serão as bibliotecas daqui um século? Continuarão com crescimento de acervos, agregando novos suportes, formatos, ações e missões, ou estarão interligadas de tal maneira que o leitor poderá transportar-se virtualmente para gigantescos acervos, com segurança e facilidade advindas de novas técnicas e tecnologias, ao romper conceitos de espaços e tempos?

Provavelmente novos métodos e metodologias estarão presentes e pessoas continuarão a ser a essência desta organização que ganha o "sopro de vida" e tem sua própria história contada pela aquisição ou incorporação de acervos e o leitor desenhará novas idéias e resgatar-se-á experiências para tornarem-se milenares.

\subsection{Da presença física à interação cultural}

Espaços para encontros do leitor e de suas leituras precisam ser cultivados com cuidado, planejados com harmonia, pautados não só na estética do ambiente como na estética da literatura, na ética do ser e não apenas no ter, observando a ergonomia para facilitar a acessibilidade, usabilidade e disponibilidade do acervo.

Fontes de leitura e fontes de referências são os materiais da produção cultural, educacional. Provocam o capital intelectual e este dinamiza e gera a economia, possibilita reduzir a violência. Amplia horizontes ao remover as viseiras da ignorância e estimula encontros entre leitores e autores, baseados nos sabores dos saberes. 
Da presença física descortina-se o espaço, o deslocamento, o acesso e principalmente as políticas de uso do acervo, transformado conforme as evoluções, as necessidades dos indivíduos, o desenvolvimento cultural e educacional de um povo.

Bibliotecas precisam ocupar espaços e dinamizá-los ao uso: por meio de visitas orientadas, pessoas preparadas (conheçam o seu público e interajam positivamente), ofereçam oportunidades para a educação continuada, a leitura, o lazer.

\subsection{Digital e novas tecnologias da informação e comunicação}

Bibliotecas nas quais existiam imensos catálogos estão sendo transformadas em espaços de conexão para Internet, mesas e pontos de conexões e visam até mesmo disponibilizar equipamentos e softwares.

Os catálogos em rede de computadores podem ser acessados de casa, do trabalho ou mesmo na biblioteca. Para isso é preciso conhecer o mundo da informática. Não é necessário ser um especialista, mas saber operacionalizar softwares em diferentes equipamentos, como teclado, monitor, microfones, alto-falantes, impressoras, recursos de armazenamento (disquete, drivers, DVD, CD-ROM, entre outros) ou até mesmo disponibilizar conteúdos em sites.

As fontes de informação estão cada vez mais diversificadas, na tipologia documental, nos suportes e formatos. É preciso saber o que se busca e por onde começar. Navegar é preciso, mas tendo rumo e objetivo, com bons instrumentos em forma de catálogos virtuais, bibliotecas digitais e virtuais, mecanismos de busca. Objeto digital estará na tela. Entre os recursos estão os catálogos de catálogos para recuperar o essencial com rapidez e eficiência, apontar a disponibilidade da obra e escolher a mais próxima ou solicitar para a biblioteca a obra. O Catálogo Virtual de Karlsruhe - Karlsruher Virtueller Katalog - http://kvk.uni-karlsruhe.de/ tem esta praticidade. Basta saber selecionar. 
A cooperação e interatividade desafiam o desenvolvimento de bases de dados e ferramentas de busca para atender demandas específicas. Por exemplo, a ZBD - maior base de dados de títulos de revistas - arrola 1.200.000 títulos desde 1500 e informações sobre cerca de 4.300 bibliotecas da Alemanha.

\subsection{Violência e leitura}

Com a violência aumentando em diferentes localidades e até mesmo entre nações, as bibliotecas se tornam pontos de encontros para o acesso e uso de acervos e são um espaço social para o encontro com o saber.

Noutros momentos as próprias bibliotecas são saqueadas na primeira oportunidade, quer seja por desastres naturais como o furacão Katrina em New Orleans ou pela estupidez, ambição e ignorância dos tempos de guerra - a biblioteca de Bagdá. Pela ganância e cobiça comercial, documentos de bibliotecas e arquivos são furtados aos poucos como no caso do Rio de Janeiro.

Para serem pontos de encontro de pessoas e de idéias, os multimídias precisam estar preparados para receberem pessoas, equipamentos (máquinas e softwares), ergonomicamente projetados ou pelo menos adaptados. Não se pode admitir que ainda sejam inauguradas sem espaços com requisitos mínimos de acessibilidade para portadores de necessidades especiais (auditivas, visuais, motoras), ou bibliotecas universitárias sem toaletes. As bibliotecas devem oferecer informação com adequação, considerar as condições climáticas e tornar ambientes apropriados para compartilhar as diversas artes, ciências, crenças.

Martinez (2005) menciona a situação na Colômbia em que o fechamento da Biblioteca Nacional ao público geral, levou a reforçar nas bibliotecas públicas as coleções de materiais sobre aspectos da cultura geral, das artes e das técnicas, da vida cotidiana, da culinária, da cosmética, costura, vestuário, lazer e trabalho, literatura, divulgação da ciência. A música era o foco 
central, com uma ampla coleção de partituras clássicas e populares, gravações de vídeo, discos laser e digitais, etc., que podem ser apreciados nas cabines com equipamento apropriado.

[...] Desde 2000 os livros são pedidos pelo correio eletrônico, e entregues nas residências dos leitores. Os usuários podem pegar e devolver os livros em quaisquer das 19 bibliotecas da rede do Banco de la República em todo o país.

[...] O desenvolvimento dos mecanismos para conservação e distribuição da informação digital constitui o mais importante elemento no mundo das bibliotecas. A rede permite que os serviços de uma biblioteca cheguem a usuários distantes, em locais em que seria impossível atendê-los diretamente.

[...] Rede Capital de Bibliotecas Públicas do Distrito Capital (Santa Fé de Bogotá). É um sistema integrado por 3 (três) bibliotecas maiores (com aproximadamente $13.000 \mathrm{~m}$ localizadas em pontos estratégicos da cidade, 6 (seis) bibliotecas intermediárias (de aproximadamente $6.000 \mathrm{~m}$ e 10 (dez) bibliotecas descentralizadas (de aproximadamente $3.000 \mathrm{~m}$ nos bairros, totalmente conectadas entre si. Cada biblioteca é um importante centro cultural e "ponto de encontro" da comunidade, gratuito e de fácil acesso para os habitantes da cidade. Resgata espaços abertos e fechados dedicados à informação, educação, leitura e criatividade. Nesta rede são oferecidos mais de 250.000 volumes e atendidos mais de 200.000 usuários por mês. (MARTINEZ, 2005).

Os acervos históricos e culturais transformam-se até mesmo em pontos turísticos, devido a serem vistos como espaços de acesso à informação, de preservação da cultura e da memória de um povo. São pontos de referência dentro da comunidade e no próprio país. As bibliotecas públicas, nacionais, universitárias tornaram-se espaços educacionais para toda a vida. Eis exemplos de bibliotecas que são temas de filmes, livros e visitas constantes como a pública da cidade de Nova York - http://www.nypl.org/, do Congresso http://www.loc.gov/, Biblioteca Nacional da França - Paris - http://www.bnf.fr/, Biblioteca Nacional da Alemanha - http://www.d-nb.de/, Biblioteca Britânica - http://www.bl.uk/, Biblioteca Nacional da Austrália - http://www.nla.gov.au/, Biblioteca Nacional de Portugal - http://www.bn.pt/, Biblioteca Nacional do Brasil - http://www.bn.br.

\subsection{Cooperação, tecnologia e tendências}

A tendência das bibliotecas baseia-se na cooperação, na busca de parcerias, no uso de tecnologias para aproximar pessoas, culturas e ciência. 
A experiência de Portugal referente ao trabalho cooperativo, conforme exposto no Foro (2002), observa que ao comemorar 15 anos, em janeiro de 2002, a Rede Nacional de Bibliotecas Públicas (RNBP) já integrava 227 dos 278 municípios e que as "bibliotecas que integram a Rede são dimensionadas em função do número de habitantes de cada conselho, de acordo com três programas-tipo que definem a área útil a afectar aos diferentes serviços, o número de documentos exigidos e o quadro mínimo de pessoal tecnicamente habilitado”, conforme visto no quadro abaixo.

\begin{tabular}{|c|c|c|}
\hline & Concelhos & Área \\
\hline $\begin{array}{ll}\text { Biblioteca } & \text { Municipal } \\
\text { de tipo } 1 & \end{array}$ & até 20000 hab. & $702 \mathrm{~m} 2$ \\
\hline $\begin{array}{ll}\text { Biblioteca } & \text { Municipal } \\
\text { de tipo } 2 & \end{array}$ & de 20000 a 50000 hab. & $1321 \mathrm{~m} 2$ \\
\hline $\begin{array}{l}\text { Biblioteca } \text { Municipal } \\
\text { de tipo } 3\end{array}$ & mais de 50000 hab. & $1885 \mathrm{~m} 2$ \\
\hline
\end{tabular}

Fonte: http://www.picbip.org/sb.jsp?id_seccion=3\&id_pais=18

Quadro 1 Tipologia de bibliotecas do Projeto Bibliópolis de Portugal

Ao analisar o Quadro 1, observa-se como Portugal tem buscado alternativas para aproximar bibliotecas nas comunidades. Pergunta-se aos colegas brasileiros: como criar bibliotecas e tornar-se um país de leitores quando falta vontade e coragem aos representantes políticos em estabelecer políticas públicas de acesso e uso da informação em seus diferentes suportes para a população? Lindoso (2004) explica o descaso, o gasto público e o desleixo que isso provoca na cultura de uma nação.

Villalba (2005a) menciona em sua reportagem que no Brasil existem mais de 14 milhões de pessoas vivendo em cidades nas quais não existe uma biblioteca sequer. Além disso, milhões de brasileiros são analfabetos funcionais - não conseguem preencher formulários ou emitir opinião após a leitura de um texto informativo. 
A biblioteca precisará utilizar e disponibilizar recursos informacionais e novas tecnologias para a comunidade. Desenvolver relações internas e externas, estimular a cooperação e união entre serviços de bibliotecas. Contar com pessoas dinâmicas, comunicativas (verbal, escrita e no uso das telecomunicações). Coordenar e integrar a bases de dados, promover iniciativas sobre a informação digital e virtual nas instituições, conduzir políticas e procedimentos sobre a organização e acesso à informação digital, delinear diretrizes para planejar a preservação da informação digital em longo prazo, gerenciar arquivos eletrônicos em sistemas de arquivos abertos. Tratar de softwares para migração de registros eletrônicos, observando conteúdos digitais, as estruturas da rede de computadores local e externa, utilizar a descrição representativa da informação por meio de metadados, buscar plataformas de softwares e hardwares em rede de computadores adequados à necessidade da biblioteca.

O ambiente da biblioteca precisa estar preparado para mudanças de origem tecnológica e também novas exigências no relacionamento com as pessoas. Ao exercer suas atividades e tarefas o bibliotecário necessitará de habilidades operacionais para efetuar o controle bibliográfico da informação. Compreenderá a comunidade a ser atendida, aplicará técnicas de avaliação, desenvolverá políticas e procedimentos, entender de análise financeira e orçamentária, analisará criticamente e proporá soluções aos problemas e na tomada de decisões e negociações.

\section{CONCLUSÕES}

As bibliotecas desde a antigüidade buscam a preservação da memória e do saber. Precisamos estar alerta para as mudanças da vida e também na administração de bibliotecas.

Aumentar a eficiência no atendimento de pessoas e respeitar os valores culturais são elementos básicos para acompanhar a velocidade das mudanças.

(C) Revista Digital de Biblioteconomia e Ciência da Informação, Campinas, v. 4, n. esp., p. 56-71, 2006 - ISSN: 1678-765X. 
Se não tivermos acervos significativos (qualitativos) e com ações para uso, quem usará os serviços de uma biblioteca?

A cooperação seja ela local, regional, nacional e internacional estará presente no desenvolvimento de coleções e acervos. A adoção de normas e padrões bibliotecários, de tecnologias, de diretrizes para facilitar o planejamento, a organização, tratamento, disseminação, recuperação, acesso e uso da informação visam atender satisfatoriamente os leitores.

A globalização é real e está presente também nas bibliotecas. Se antes eram necessários idiomas como o grego, latim e árabe, no momento o inglês e a linguagem de informática são dominantes.

Para os ávidos em leituras precisamos de acervos adequados, pois as leituras desenvolvem o aprendizado e favorecem as escolhas da vida.

Censura de leituras e acessos não autorizados não combinam com a demanda de circular a informação. Em transformá-la para uma vida melhor. Bibliotecas devem estar na pauta de políticas públicas de acesso à informação e inclusão social e digital. Não se pode continuar a exclusão social de muitos e continuar com privilégios de determinados grupos ao acesso da informação. Livros restritos e livros proibidos resgatam situações de violência ao ser humano, a não respeitar o direito à informação. Não se pode viver mais uma "época que poucos sabiam muito e muitos sabiam pouco".

As bibliotecas são instituições frágeis e precisam de cuidados, pois são cercadas de perigos (roubos, fogo, água) e na era da Sociedade da Informação é necessário preservar conteúdos, formas e formatos, observar as condições das redes de transmissão de dados, da velocidade (lentidão), segurança (problemas técnicos de compatibilidade e interoperabilidade) e adequação do ambiente para o armazenamento e a recuperação de informações. Novas preocupações: utilizar a ergonomia no ambiente (acessibilidade, 
disponibilidade e usabilidade) e no uso da informação, documentos requerem a aplicação de critérios de harmonização: no estilo da escrita, da fonte, da cor do texto e do fundo, do uso de elementos de hipermídia (áudio, clipes de vídeo, animação, etc.) com moderação e bom senso.

O desenvolvimento social e a penetração da leitura nas comunidades da aldeia global partem, sem dúvida das bibliotecas. Hoje, mais do que nunca, se reconhece que essa instituição exerce um papel vital na educação e na formação das pessoas. Daí, a necessidade de conhecê-la melhor. Para que isso aconteça, é absolutamente necessário que as portas das bibliotecas estejam abertas para todos os cidadãos.

\section{REFERÊNCIAS}

AUGUSTO, S. Habemus papirum : Manuscritos achados na cidade grega de Oxirrinco podem redesenhar perfil da civilização clássica. O Estado de São Paulo, 24 abr. 2006. Aliás. Disponível em: <http://txt.estado.com.br/editorias/2005/04/24/ali010.xml >. Acesso em: 12 jul. 2006.

BATTLES, M. A conturbada história das bibliotecas. Tradução João Vergílio Gallerani Cutter. São Paulo: Planeta do Brasil, 2003.

BIBLIOTHEKSSERVICE-ZENTRUM Baden-Wuerttemberg (BSZ). Recherche in der Digitalen Bibliothek Baden-Württemberg. 2006. Disponível em: <http://www.digibibbw.de/servlet/Top/searchadvanced>. Acesso em: 14 jul. 2006.

BIBLIOTHEKSSERVICE-ZENTRUM Baden-Wuerttemberg (BSZ). SWB Online-Katalog. 2006. Disponível em: <http://pollux.bsz-bw.de/>. Acesso em: 14 jul. 2006.

BIBLIOTHÈQUE Nationale de France. Gallica: Código documental. 2006. [Espanhol]. Disponível em: <http://www.bnf.fr/pages/zNavigat/frame/version_espagnole.htm? ancre=espagnol.htm> . Acesso em: 09 jul. 2006. 
BLATTMANN, U. Visita a Bibliotecas na Alemanha. Revista ACB: Biblioteconomia em Santa Catarina, v. 10, n. 2 , p. 269-264, jan. dez. 2005. Disponível em: $<$ http://www.acbsc.org.br/revista/ojs/viewarticle.php?id=127\&layout=abstract >. Acesso em: set. 2006.

; FRAGOSO, G. (orgs.). O zapear a informação em bibliotecas e na Internet. Belo Horizonte: Autêntica, 2003.

CIMIERI, F. Mais de um bando atacou museus, diz delegada. O Estado de São Paulo, 11 jul. 2006. Metrópole. Disponível em: <http://txt.estado.com.br/editorias/2006/07/11/cid1.93.3.20060711.27.1.xml?>. Acesso em: 12 jul. 2006.

CUNHA, M. B. Para saber mais: fontes de informação em ciência e tecnologia. Brasília: Briquet de Lemos/Livros, 2001.

ECO, U. O nome da rosa. Trad. Aurora Fornoni Bernardini e Homero Freitas de Anfrade. Rio de Janeiro: Nova Fronteira, c1983. [Título original: Il nome della rosa. 1980].

FORO Iberoamericano de Responsables Nacionales de Bibliotecas Públicas. Rede Nacional de Bibliotecas Públicas: Objectivos e princípios programáticos. Disponível em: $<$ http://www.picbip.org/sb.jsp?id_seccion=3\&id_pais=18>. Acesso em: 12 jul. 2006.

JEITO sisudo de Bogotá dura pouco: Primeira impressão da capital se desfaz de pronto: metrópole é rica em cultura e festa. O Estado de São Paulo, 01 nov. 2005. Viagem. Disponível em: $<$ http://txt.estado.com.br/suplementos/viag/ 2005/11/01/viag014.xml>. Acesso em: 12 jul. 2006.

JOCKEL, S. Deutsche Nationalbibliothek mit erweitertem Sammelauftrag. 2006. [Informações para imprensa de 29.06.2006]. Disponivel em: $<$ http://www.ddb.de/aktuell/presse/pressemitt_dnbg_neu.htm>. Acesso em: Acesso em: 14 jul. 2006.

LINDOSO, F. O Brasil pode ser um país de leitores? Política para a cultura / política para o livro. São Paulo : Summus, 2004. 
MARTINEZ, L. Colômbia, o país das bibliotecas. Disponível em: <http://www.criancascriativas.com.br/bliblo_artigo.pdf> . Acesso em: 12 jul. 2006.

NATIONAL Library of Austrália. Catalogue. Geospacial search. 2006. [Catálogos de imagens da Biblioteca Nacional da Austrália ] Disponível em: <http://catalogue.nla.gov.au/cgibin/Pwebrecon.cgi?PAGE=mbSearch\& SEQ=20060716020342\&PID=1599>. Acesso em: 14 jul. 2006.

ORTEGA GASSET, J. Rebelião das massas. Ed. Ridendo Castigat Mores. Disponível em: $<$ http://www.ebooksbrasil.org/REB/ortega.rb>. Acesso em: 10 maio 2006.

PAIVA, F. M. P. Golpe à brasileira: Assalto a museu carioca é enredo que junta um Picasso, uma Kombi e um bloco de carnaval . O Estado de São Paulo, 05 mar. 2006. Alias. Disponível em: $<$ http://txt.estado.com.br/editorias/2006/03/05/ali53573.xml >. Acesso em: 12/07/2006.

PAMPLONA, N. Livro raro de naturalista francês é furtado de biblioteca da UFRJ. O Estado de São Paulo, 02 mar. 2006. Metrópole. Disponível em: <http://txt.estado.com.br/editorias/2006/03/02/cid51121.xml>. Acesso em: 12 jul. 2006.

POTTER, A. B. Zones of silence: A framework beyond the digital divide by First Monday, v. 11, n. 5, May 2006. Disponível em: < http://firstmonday.org/issues/issue11_5/potter/index.html >.

RODRIGUES, A. PF apreende em leilão documentos históricos:Textos oficiais do século 19 pertencem a instituições públicas O Estado de São Paulo, 20 ago. 2006. Vida \&. Disponível em: $<$ http://txt.estado.com.br/editorias/2005/08/20/ger006.xml >. Acesso em: 12 jul. 2006.

UNIVERSITÄTSBIBLIOTHEK Karlsruhe. Karlsruher Viertueller Katalog. 2006. [Versão de 10 jul. 2006] Disponível em: < http://www.ubka.uni-karlsruhe.de/kvk.html>. Acesso em 14 jul. 2006.

VILLALBA, P. Brasil articula a Câmara Setorial do Livro e Leitura País vive momento singular pela formação de leitores. O Estado de São Paulo, 22 fev. 2005a. Caderno2. Disponível em: <http://txt.estado.com.br/editorias/2005/02/22/cad002.xml>. Acesso em: 12 jul. 2006.

(C) Revista Digital de Biblioteconomia e Ciência da Informação, Campinas, v. 4, n. esp., p. 56-71, 2006 - ISSN: 1678-765X. 
VILLALBA, P. Mário de Andrade ainda pede socorro: Mesmo com a reforma alardeada pela gestão anterior, a 2. ${ }^{\mathrm{a}}$ maior biblioteca do País agoniza - e sobrevive graças ao empenho de seus funcionários. O Estado de São Paulo, 24 fev. 2005b. Caderno2. Disponível em: <http://txt.estado.com.br/editorias/2005/02/24/cad009.xml>. Acesso em: 12 jul. 2006.

WAKIN, D. J. População luta para salvar acervos: peças valiosas de museu foram destruídas, mas voluntários e especialistas resgataram coleções importantes. O Estado de São Paulo, 05 set. 2005. Internacional. Disponível em: <http://txt.estado.com.br/editorias/2005/09/05/int005.xml>. Acesso em: 12 jul. 2006.

ZEITSCHRIFTENDATENBANK - ZDB. Was ist die ZDB. OPAC. http://www.zeitschriftendatenbank.de/index.html>. Acesso em: 14 jul. 2006.

\section{Úrsula Blattmann}

Professora no Curso de Graduação Biblioteconomia e no Programa de Pós-Graduação em Ciência da Informação (Mestrado) na Universidade Federal de Santa Catarina. ursula@ced.ufsc.br

Graça Maria Fragoso

Diretora da Biblioteca Pública Estadual Luiz de Bessa fragoso.bh@gmail.com

Recebido em: 26/07/2006

Aceito para publicação em: set. 2006 